\title{
Consideration and Exploration of Digital City to Smart City in China
}

\author{
Chengming Li \\ China Academy of Surveying and Mapping \\ Beijing, China \\ cmli@casm.ac.cn
}

\author{
Xiaoli Liu \\ China Academy of Surveying and Mapping \\ Beijing, China \\ liuxl@casm.ac.cn
}

\begin{abstract}
The study summarized primarily the necessity of constructing authoritative, unique and universal geo-spatial framework of digital city, and then introduced the general train of thought, progress, function and influence of the construction of digital city in our country. Subsequently, according to the development of era, advance of technology and changes in demand, the new development opportunities and challenges facing the current geo-spatial framework were discussed, associated with the exploration of existing problems, the highlighting of the constructing goal and content of the spatiotemporal information framework of smart city, as well as the expectation of future direction of technological breakthroughs.
\end{abstract}

Keywords-Digital city; Smart city; Spatio-temporal information cloud platform

\section{INTRODUCTION}

Mapping refers to the determination, collection and presentation of natural ge ographic factors or surface artificial facilities in shape, size, spatial location and attributes, as well as access to da ta, information, results processing and delivery activities[1], which, to be exact, is a co mposite expression of the real world. Howe ver, in the face of a continuous spac e in the real world and in view of the limitations of the $m$ eans of surveying and mapping, our continuous real world is described hierarchically and hierarchically under inertial conditions with the use of a number of broken sections, where the plotting scale can be ranged from 1:400 million and 1:1600 million to 1:1000 and 1:500 in size. Although in the 80 s of the last century, we have entered the digital phase, how $t$ o break through the thinking limitations is still the primary difficulty. Researchers are still wo rking on the creation of multi-scale geographic information databases and hard co pies, laying the space foundation for the informatization of $t$ he department, the achievement of pape rless office and corres ponding efficiency improvement at that time. With the generalization of interconnection and interworking, the developed various thematic application systems based on geographic information are affected by the time of supply, batch, reprocessing, frequency of updating and other factors, resulting in the inconformity of the benchmark, time and content of the spatial space, which in turn intensify the difficulty of inform ation integration and sharing, and even lead to information gaps of different sizes.
The city is th e main battlefield of economic construction that is characterized by the fastest development, most abundant information and highly concentrated capital. In the city, the process of informatization is advancing by leaps and bounds, indicating the strongest demand for geographic information. Nevertheless and inevitably, the city may also encounter the earliest and $\mathrm{m}$ ost serious problems mentioned above, even becoming the bottleneck in the process of informatization promotion. For example, emergency response should be integrated with a vari ety of info rmation to support decisionmaking, however the fact is that the spatial base is divided and the integration process is time-consuming, contributing to a unreliable integration results. With respect to the above, the establishment of a con tinuous, unified, authoritative, unique spatial base or geographical space framework in the city is a task which brooks no delay to support the informatization of the national economy, as well as local economic and social development.

\section{Construction of Digital City}

\section{A. General Idea}

Essentially, digital reconstruction of the continuous real world in the binary algorithm on the $(0,1)$ program is no longer appropriate with the application of plotting scales (1:500, $1: 1000,1: 2000$, etc.), even though such scales are easy for oral arithmetic and mental arithmetic of hum ans. Scales $(2 n)$ for oral and $\mathrm{m}$ ental arithmetic more in line with the current electronic computer should be adopted, such as 1, 4, 16,64 , 256 and 1024, etc.. Under the support of stepless mapping technique, integrating multi-scale data such as 1: 500 and 1:1000 can be transformed into tiles based on Pyramid model of multiple levels and $2 n$ in each order. In this way, the $r$ eal world can be expressed continuously in the digital environment, rather than some sections separated from it. Different from the original database, the present continuous expression of the real world is known as public platform for geographic information. With no doubt, considering the progress of network Topology feature technology, the platform can be existed with distributed storage, multi-node coordination and one-stop service. Meanwhile, through the confirmation of 1 ocal government documents, the platform can be est ablished as an uni fied, authoritative, unique thematic information integrated spatial base or ge ographical space framework in the city, so as to avoid repeated construction of su rveying and mapping 
geographic information, and to promote the wide application andsharing of information resources.

\section{B. Construction Situation}

The constriction of g eo-spatial framework of digital city covers one library, one platform, 2 3 applications and a set of long-term mechanism for updating, maintaining and promoting[2-4]. Since 2006, national bureau of surveying and mapping geographic information has accelerated the construction of geo-spatial framework of digital city, especially in 2009. Digital city construction has been carried out in an estimated 333 prefecture-level cities and $578 \mathrm{c}$ ounty-level cities, more than $5600 \mathrm{a}$ pplication systems have b een developed to bring benefit to over 60 fields containing territorial planning, real estate, $\mathrm{p}$ ublic security, fire, environmental protection and health, exerting an important role in the process of eco nomic and soci al development, industrialization and informatization.

\section{Role and Impact}

The geo-spatial framework of $d$ igital city has become a symbol for di splaying the city image, an im portant tool for leadership in scientific decision-making, a basic platform of urban informatization construction, an ad vanced means of product promotion as well as a co nvenient helper for improving people's quality of life.

On September 14, 2010, a continuous follow-up interview of eight pilot cities wasconducted by ten Central News Media for three months, covering a series of achi evements and the effects of applications in the co nstruction of digital cities, causing extensive and widespr ead influence in the whole society[5]. Furthermore, on May 23, 2011, premier Li Keqiang visited China's Innovation Base an $d$ fully affirmed the achievements of digital city construction. The premier minister considered that some aspects of $t$ he construction of di gital cities have ent ered advanced ranks in the world, resulting in effective and significant enhancement of the scientific and meticulous level of ur ban management, as wel 1 as the promotion of good image of the government.[6]

\section{New Situation AND New Problems}

\section{A. New Situation}

The geo-spatial framework will face new opportunities and challenges with times developing, techniques advancing and demands varying. Firstly, po sitive experience. The popularization and universalness of geo graphic information is irresistible, users are no longer confined to professionals with a certain knowledge of surveying and mapping. It has begun to spread to the general public, new products focusing on fine three-dimensional quality, panoramic image and threedimensional technology with better experience are easi ly mastered by the general public. Secondly, enhanced real-time capability. Although the public platform of geographic information in the digital city has solved the spatial continuous expression of the real world, there is a characteristic of time-lag. The development of real-time localization, spatial perception extension of I nternet of Things, radio-frequency and other techniques provide effective means to integrate real-tim e information, which enable mapping to be continuous in time dimension to reverse the past, express the present and predict the future more accurately. Thirdly, good $\mathrm{m}$ obility functionality. With the development of wireless $n$ etwork and intelligent terminal technology, taking the machine as the core will inevitably move towards the people oriented, and the coming of mobile office era $\mathrm{w}$ ill even conducive to the realtime control of anything with the purview for anyone in anywhere and at anytime in the future. Fourth, high controllability. The system will no longer adhere to the general query, location, statistics, analysis, but make a de eply excavation of knowledge, support scientific decision-making, and issue commands for remote control relying on Internet of Things and Sensor Network, etc., thereby react to the real world through the analytical judgment of the digital world. Fifth, abundant autonomy. From the point of view of practical application, the sy stem can analyze scientifically and accurately when common users make requests, meanwhile, data resources, software, computing resources and network resources distributed on each ne twork node can be collected automatically to realize intelligent combination with knowledge-based impelling force, and to serve for the needs of the society.

\section{B. New Problems}

First of all, although nodes of Internet of Things such as video and wireless-radio have realized the spatial location and opened the window for real-time access, there is still a need to extract and integrate information organically with the geographical information, so as to fully support spatial analysis decision-making. Secondly, due to difficulties in environmental construction, talent deficiency and i nsufficient updates, the weak GIS application departments are expected to imple ment data, software and computing on-demand applications in a host manner. Finally, as for the authoritative, unique and common public platform for geographic information at present, there is a lack of pers onalized platform customization capabilities although it reflects the common needs of various departments.

\section{Situation at Home and Abroad}

Currently, all countries all around the world are trying to seize this historic opportunity and developmental chance. In 2008, the chi ef executive officer of IBM Greater C hina, pioneered the concept of "s mart earth" in a speech[7], to achieve a m ore thorough perception, more comprehensive interoperability, and more in-depth intelligence relying on modern information technology, which immediately received the high attention of the Obama administration and rai sed to the national strategy of the United States. In 2000, the European Union launched th e Ambient Intelligence (AMI) project to promote the construction of regional Internet of Things. Furthermore, in 2011, to promote local intelligence of the local region, emergency response intelligence system has been set up in Rio De Janeiro, Brazil; meanwhile, Japan, South Korea, Singapore and other Asian countries have also started a new generation of network development strategy to accelerate the process of ur ban informatization. Simultaneously, Shenyang, Kunshan and other cities in China have carried out the exploration and practice of smart city. 
Even though different countries may have different intentions and purposes to start the similar project, there is a central idea that based on a variety of modern technologies, each individual and organization of the whole society can provide and acquire information, as well as mine knowledge freely, accurately, conveniently, and prom ptly. Meanwhile, positive influence can be exerted on the behaviors of each other to achieve the macro effect of operation of wi sdom, thus promoting the change of the whole industry and the whole public service system.

\section{Enlightenment}

To adapt to the new situation brought by technological advances and demands development, and to catch up with the developed countries to start on the same starting line, the informatization construction of our country must proceed from digital to smart, and push the construction of digital city to smart city. Besides, advances in cloud computing, the Internet of Things, sensors and other related technologies make this possible. Moreover, it also requires further improvement of geo-spatial framework to effectively support the construction and operation of the smart citythat it is th ereby capable of being a new orientation for urban "brain" and "skeleton". To be specific, the main function of geo-spatial framework improvement includes two aspects: first, responsible for the integration, processing, visualization, analysis and decision of spatial location information; and second, accurate location of nodes of real-time perception information in the Internet of Things.

\section{CONSIDERATION OF SMART CITY}

\section{A. Awareness and Understanding}

Different countries, regions and industries may have different understanding of smart city. From the perspective of surveying and mapping, we consider that smart city refers to the process of materialization of human knowledge into the activities of urban planning, designing, construction, management, operation and development under the condition of informatization, which is su pported by sp atio-temporal information and relying on modern information technology, such as Internet of Things and cloud computing, so as to form intelligent topics that do not depend or rely less on pe ople, followed by the on-demand optimization to achieve organic coordination with each other[8-9]. A smart city should include real-time information sensing devices like the hum an senses, bidirectional transmission network system of information and instruction like the human nervous system, the cloud computing center like the human brain, response and disposal thematic system like the human behavioral organs.

Smart city is the vision of the development of urban informatization, and it will un dergo different stages of development from elementary to advanced, from local to whole, and from single to comprehensive.

\section{B. Differences}

Compared with digital cities, smart cities reveal a highquality development. In the phase of digital city, it is mainly presented as "distributed and one-stop", without centralization of the data and with distributed storage, the logic integration is realized through the network, thereby providing one-stop service to the user; besides, it also has some other features as follows: "digital, networked, spatial and collaborative", various topics are digitized firstly, and integrated into a unified space, online operation is completed on the basis of the network to achieve collaborative office of rela ted business. In the stage of smart city, corresponding major characteristics are "Infrastructure as a service (Iaas), Software as a service (Saas), Platform as a service (Paas)"[10], and "Activation, virtualization, agency and spirituality". based on the integration of Internet of Things and perception real-time information, virtualization of shared infrastructures, services on demand can be provided by proxy host resources and smart combinations.

\section{Location of Mapping Department}

Digital city and smart city are inseparable from the support of the geographical space fram ework. The geo-spatial framework is the responsibility of the geographic information departments of surveying and mapping, and also the infrastructure of city informatization.

In the digital city phase, the main contents of the geospatial framework are pre sented as the basic geogra phic information database and the public platform for geogra phic information. With the development of Internet of Things and cloud computing, the basic geographic information database transforms to spatio-temporal nformation database, and the public platform of geog raphic information rises to the spatiotemporal information cloud platform. By comparison, in the phase of sm art city, the geo-spatial framework has temporal and spatial characteristics which is d eveloped into spatiotemporal information framework, corresponding core content covers spatio-temporal information database and spat iotemporal information cloud platform.

Among them, spatio-temporal information database consists of four parts: spatio-temporal information data, node address data in the Internet of Things, spatio-temporal information database management system and supp orting environment. On the other hand, on the basis of visually expressed fine geographical information and temporal geographic information covering the entire society, the spatiotemporal information cloud platform can offer a servi ce on demand of geographic information, Internet of T hings, node positioning, functional software and interface development for the ubiquitous application environment. The spat io-temporal information cloud platform includes four parts: spatio-temporal data service, Internet of Th ings, node location service, cloud service system and cloud computing service center.

Compared with the public platform of geographic information, the spatio-temporal information cloud platform has characteristics of better experience, more real-time, greater mobility, higher controllability and aut onomy. The spat iotemporal information cloud platform is no longer just a snapshot of the real world, but a sp atial information with temporal dimensions, and a continuous reproduction of the living world; at the same time, it is $\mathrm{n}$ o longer the digital 
reconstruction of the real world, but can depend on the Internet of Things to react to the real world.

Thus far, in accorda nce with the above construction ideas and concepts, national administration of surveying, mapping and geographic information has organized more than 40 cities to carry out the construction of s patio-temporal information cloud platform of smart city.

\section{CONCLUSION}

From the development of digital city to the smart city, the future breakthroughs in technology at least include the following three aspects: first, from the real-time access of perceptual information to organic integration and de ep utilization; second, from distributed storage and logic centralization of reso urces to cloud computing and host resources; third, from service docking to knowledge engine and on-demand service. In combination with the existing geospatial framework of the digital city, the expansion, addition or upgrading of data in the function and performance will drive it from quantity to quality, resulting in another upgrading and transformation to support the construction and operation of a smart city.

\section{ACKNOWLEDGMENT}

This paper was Supported by the National Surveying and Mapping Burea (A1705) and The Nat ional Key Technology R\&D Program (2015BAJ06B01).

\section{REFERENCES}

[1] Surveying and M apping Law of the People' $s$ Republic of China[S].Beijing:China Legal Publishing House, 2002

[2] State Bureau of Sur veying and M apping.CH/T 9003-2009 Basic specifications for geo-spatial fr amework[S].Beijing:Surveying and Mapping Press, 2009

[3] State Bureau of Sur veying and Mapping.CH/T 9004-2009 Basic specifications for common platform of geographic information[S].Beijing:Surveying and Mapping Press, 2009

[4] State Bureau of Sur veying and Mapping.CH/T 9005-2009 Basic Specifications for Fundamental Geographic Information Database[S].Beijing:Surveying and Mapping Press, 2009

[5] Zhao Yahui, Shen Yin, et al. Digital city, better life![N].People's Daily, 2010-11-21(1)

[6] Li Weisen. Analysis of inn ovation in the constr uction of geo- spatial framework of Di gital City [J].Bu lletin of Sur veying and M apping, 2011(9): $1-5$

[7] Peng Mingsheng. Earth of wisdom: the agenda for the next generation of leaders[R]. New York: Council of Foreign Relations, 2008-11-6

[8] Li Chengming. Spatio-temporal information cloud platform of s mart city[EB/OL].

2012-6-4 http://www.cbinews.com/cloudchanel/news/2012-06-04/187453.htm.

[9] Li Chengming. Location and fu nction of geo graphic information in smart city [E B/OL].2012-6-13. http://www.labs.chinamobile.com/news/73542

[10] Zhao Liwei, Fang Guowei, et al. Let cloud within reach-Pra ctice guidelines for Mi crosoft's cloud co mputing framework[M]. Beijing: Publishing House of Electronics Industry, 2012. 